\title{
Original Article \\ Comparative study of day 01 spica cast versus skin traction followed by spica cast for treatment of closed femoral shaft fracture in children
}

\author{
Ripon Kumar Das, ${ }^{1}$ Md Johurul Hoque, ${ }^{2}$ Md Emam Zamman, ${ }^{3}$ Fakhrul Islam ${ }^{4}$
}

\begin{abstract}
:
Femoral shaft fractures are among the commonest fracture of lower extremity in children and commonly require hospital admission. There are various modalities of treatments both operative and non-operative. The aim of treatment is to secure union, in good alignment with length restored and early rehabilitation. objective of this study was to compare the results of day 1 spica cast and skin traction followed by spica cast in the treatment of femoral shaft fractures in children ( 6 months to 10 years). A total of 64 patients with fracture shaft femur of either sex aged 6 months -10 years with closed, isolated diaphyseal femur fracture were included in this study. Case with clinical evidence of infection, pathological fractures and multiple injuries including neurovascular injuries were excluded from the study. The patients were randomly assigned into two groups, Group -1 (n-32) patients who underwent early spica application while Group -2 ( $\mathrm{n}-32)$ patients underwent skin traction in followed by spica cast. Mean age in group A was 5.06 years and 5.12 years in group B (range 6 month - 10 years). Ratio of males and female in Group A and Group B was 19:13 and 20:12 respectively. Average duration of hospital stay was 1.65 days and 11.65 days in group A and group B respectively. Average total time of spica cast application was 45.13 days 49.41 days in group A and group B patients respectively. There were no significant differences between early and delayed spica regarding the complications of treatment and functional outcome. But immediate spica decreased the hospitalization time and the cost of treatment significantly with increased availability of beds while having similar result as achieved by delayed spica application.
\end{abstract}

Keywords: Femur, Fracture, Hip spica, Traction.

\section{Introduction:}

Femoral shaft fractures can occur in children of all ages. They account for $1.6 \%$ of all children fractures, and they lead to significant impact on the child and family ${ }^{1}$. Direct or indirect loading of diaphysis of a femur may result in fractures. Direct hit on the thigh by an automobile results in direct violence leading to fracture which is transverse or with butterfly fragments, whereas indirect violence or rotational force results in spiral or oblique fracture of diaphysis of femur ${ }^{2,3}$. The etiology of the femoral shaft fracture varies with the age of child with the fall from height and the road traffic accident being the most common cause ${ }^{4,5}$. The diaphysis of femur has an excellent blood supply and therefore good healing potential and due to the extensive musculature surrounding it cause displacement ${ }^{6,7}$. Hemorrhagic shock and secondary anemia are the most important early complications, whereas the late complications include prolonged recumbency, joint stiffness, malunion, nonunion, leg length discrepancy and infection ${ }^{8}$. The aim of treatment is to secure union, in good alignment with length restored and early rehabilitation'. Various methods of treating femur shaft fractures in children are pelvic harness, Padding, hip spica cast, skin traction (can be followed by hip cast), skeletal traction, elastic intramedullary nails and semi-rigid pediatric locking nail ${ }^{10,11}$. In children spica casting or initial traction followed by spica casting an effective treatment modality, largely because they have a tremendous ability to remodel the deformities that remain after closed treatment in remodeling stage of fracture healing ${ }^{12}$. A number of variables including age and weight of the child, type of fracture, associated injuries or polytrauma and socioeconomic status of the family affect the decision to manage a femoral shaft fracture by conservative or operative means ${ }^{13}$.

\section{Methods and Materials}

A comparative study was conducted at Z.H Sikder women's medical college hospital, Dhaka from July

1. Assistant Professor, Department. of Orthopedics, Z.H Sikder Women's Medical College \& Hospital, DHAKA.

2. Associate Professor, Department. of Orthopedics, Z.H Sikder Women's Medical College \& Hospital, DHAKA.

3. Registrar, Department. of Orthopedics, Z.H Sikder Women's Medical College \& Hospital, DHAKA.

4. Professor, Department. of Ophthalmology, Z.H Sikder Women's Medical College \& Hospital, DHAKA.

Address of correspondence:

Dr. Ripon Kumar Das, Assistant Professor, Department. of Orthopedics, Z.H Sikder Women's Medical College \& Hospital, Dhaka, Mobile No: 01717230280; E Mail: drripondmc@gmail.com 
2017 to July 2018. This study consists of 64 patients of either sex with fresh ( Upto one week from time of injury) isolated closed diaphyseal fractures of femur from 06 months to the age to 10 years. Children less then 06 months of age and older than 10 years, Open fractures, Infected case, Poly trauma cases, Pathological fractures, Multiple and segmental fractures were excluded from study. The patients were randomly divided into two groups. Group A was consisted of 32 patients who were treated by day 01 spica cast. Hematoma infiltration with $2 \%$ xylocain with 22 gauge needle and midazolam sedation was given for muscle relaxation.Fracture was assessed by c-arm for the the alignment and angulation correction. Traction and counter traction was applied by two assistants. Group B was consisted of 32 patients which were treated with initial skin traction followed by hip spica cast. The injured limb was put on skin traction using weight appropriate for age, limb position was adjusted with sand bags. X-ray were taken after 5-7 days of skin traction to check fracture alignment. After 7-21 days of traction, when fracture had become sticky, well moulded one and half spica was applied under GA. Parents were given instruction regarding spica care before discharging the patients. Regular follow up at $01,04,06,10$, and 12 weeks. At every visit spica was checked for cracks and skin of child was examined. X-ray were taken at 06, 10 and 12 weeks. Clinical examination was performed after removing the cast to evaluate gait, limb length discrepancy and malalignment. For data entry and analysis statistical software SPSS 20.0 was used. Statistical comparison between Group A and Group $\mathrm{B}$ was performed by using Chi square for qualitative variables and students test for quantitative variables.

\section{Results}

A total of 64 children were included in the study with 32 children in each group. Mean age in group A was 5.06 years (range 06 months to 10 years) and 5.12 years ( ranges 06 months to $10 \mathrm{yrs}$ ) in group B ( Table 1). Ratio of males and female in group A and group B was 19:13 and 20:12 respectively. Right side was involved in 15 and 14 patients in group $A$ and $B$ respectively wheres 17 and 18 patients had left side involvement in group $\mathrm{A}$ and $\mathrm{B}$ respectively. The mechanism of injury was fall from height in 14( $43.75 \%)$, RTA in $5(15.62 \%)$, fall of object in $8,(25 \%)$ sports injury in $3(9.37 \%)$ and hit by animals was seen in $2(6.25 \%)$ in Group A Patients wheres in Group B Patients fall from height, RTA, Fall of object, sports injury and hit by animals was seen in (15,5,7,3 and 2 patients respectively). Proximal, middle third and distal third fracture was seen in 9,12 and 11 patients in Group A and 11,11 and 10 patients in Group B. Level of fracture: Spiral, Oblique and transverse fracture was seen in 12,10,10 in group A children and 13,10 and 9 in group $B$ children respectively.

Table 1: Demographic Characteristic according to treatment group

\begin{tabular}{|c|c|c|c|}
\hline \multicolumn{2}{|c|}{ Demographic characteristic } & $\begin{array}{c}\text { Group A Hip } \\
\text { spica cast } \\
(n=32)\end{array}$ & $\begin{array}{c}\text { Group B } \\
\text { Initial traction } \\
\text { followed by } \\
\text { hip spica cast } \\
(\mathrm{n}=32)\end{array}$ \\
\hline \multicolumn{2}{|c|}{ Number of patients } & $32(50 \%)$ & $32(50 \%)$ \\
\hline \multicolumn{2}{|c|}{ Average age(years) } & 5.06 & 5.12 \\
\hline \multirow{5}{*}{ Age (years) } & $0-3$ & $6(18.75 \%)$ & $7(21.87 \%)$ \\
\hline & $3-5$ & $11(34.37 \%)$ & $10(31.25 \%)$ \\
\hline & $5-7$ & $7(21.87 \%)$ & $7(21.87 \%)$ \\
\hline & $7-8$ & $5(15.62 \%)$ & $5(15.62 \%)$ \\
\hline & $8-10$ & $3(9.37 \%)$ & $3(9.37 \%)$ \\
\hline \multicolumn{2}{|c|}{ Gender M/F (\% of patients) } & $19: 13$ & $20: 12$ \\
\hline \multicolumn{2}{|c|}{ Side (L/R) (\% of patients) } & $15: 17$ & $14: 18$ \\
\hline \multirow{3}{*}{$\begin{array}{c}\text { Types of } \\
\text { fracture }(\% \text { of } \\
\text { patients) }\end{array}$} & Spiral & $12(37.5 \%)$ & $13(40.62 \%)$ \\
\hline & Oblique & $10(31.25 \%)$ & $10(31.25 \%)$ \\
\hline & Transverse & $10(31.25 \%)$ & $9(28.12 \%)$ \\
\hline \multirow{5}{*}{$\begin{array}{l}\text { Mechanism of } \\
\text { injury (\% of } \\
\text { patients) }\end{array}$} & RTA & $5(15.625 \%)$ & $5(15.62 \%)$ \\
\hline & $\begin{array}{c}\text { Fall from } \\
\text { height }\end{array}$ & $14(43.75 \%)$ & $15(46.87 \%)$ \\
\hline & Fall of object & $8(25 \%)$ & $7(21.87 \%)$ \\
\hline & Sports injury & $3(9.37 \%)$ & $3(9.37 \%)$ \\
\hline & $\begin{array}{l}\text { Hit by } \\
\text { animals }\end{array}$ & $2(6.25 \%)$ & $2(6.25 \%)$ \\
\hline \multirow{3}{*}{$\begin{array}{c}\text { Level of } \\
\text { fracture }(\% \text { of } \\
\text { patients) }\end{array}$} & Proximal & $9(28.12 \%)$ & $11(34.37 \%)$ \\
\hline & Middle third & $12(37.5 \%)$ & $11(34.37 \%)$ \\
\hline & Distal third & $11(34.37 \%)$ & $10(31.25 \%)$ \\
\hline
\end{tabular}

Limb length discrepancy:

Among children in group A no discrepancy was seen in $27(84.37 \%)$, and discrepancy of $2-3 \mathrm{~cm}$ was seen in 5 children (15.62\%). Whereas among children in group B no discrepancy was seen in $30(93.75 \%)$, and discrepancy of $2-3 \mathrm{~cm}$ was seen in 2 children $(6.25 \%)$. None of the children in either had discrepancy of more than $3 \mathrm{~cm}$.

Table 2: Limb length discrepancy

\begin{tabular}{c|c|c|c}
\hline $\begin{array}{c}\text { Limb length } \\
\text { discrepancy }\end{array}$ & $\begin{array}{c}\text { Group A }(\mathrm{n}= \\
\text { 32) Hip spica } \\
\text { cast }\end{array}$ & $\begin{array}{c}\text { Group B }(\mathrm{n}=32) \text { Initial } \\
\text { traction followed by hip } \\
\text { spica cast }\end{array}$ & P value \\
\hline No discrepancy & $27(84.37 \%)$ & $30(93.75 \%)$ & 0.236 \\
$2-3 \mathrm{~cm}$ & $5(15.62 \%)$ & $2(6.25 \%)$ & \\
$3-4 \mathrm{~cm}$ & 0 & 0 & \\
$>4 \mathrm{~cm}$ & 0 & 0 & \\
\hline
\end{tabular}


Angulation: Among children in group A angulation of $10-15^{\circ}$ was seen in $24(75 \%)$, angulation of $15-20^{\circ}$ was seen in 6 children $(18.75 \%)$ and angulation of more than $20^{\circ}$ was seen in $2(6.25 \%)$. Whereas among children in group B angulation of $10-15^{\circ}$ was seen in $22(68.75 \%)$, angulation of $15-20^{\circ}$ was seen in 8 children ( $25 \%$ ) and angulation of more than $20^{\circ}$ was seen in $2(6.25 \%)$.

Table 3: Angulation

\begin{tabular}{c|c|c|c}
\hline Angulation & $\begin{array}{c}\text { Group A (n= 32) } \\
\text { Hip spica cast }\end{array}$ & $\begin{array}{c}\text { Group B (n= 32) Initial } \\
\text { traction followed by } \\
\text { hip spica cast }\end{array}$ & P value \\
\hline $10-15$ & $24(75 \%)$ & $22(68.75 \%)$ & 0.679 \\
$15-20$ & $6(18.75 \%)$ & $8(25 \%)$ & \\
$>20$ & $2(6.25 \%)$ & $2(6.25 \%)$ & \\
\hline
\end{tabular}

Range of movements (Hip and Knee at 6 week): In Group A, 4(12.5\%) children were having free range of movements at hip and knee at 6 weeks, while 26 $(81.25 \%)$ patients have decreased range of movements by $20^{\circ}$ and $2(6.25 \%)$ patient developed decreased range of movements more than $20^{\circ}$. Where as in patients of Group B, 6 (18.75\%) patients were having free range of movements at hip and knee at 6 weeks, while $24(75 \%)$ patients have decreased range of movements by $20^{\circ}$ and $2(6.25 \%)$ patient developed decrease in range of movements of more than $20^{\circ}$.

Table 4: Range of movements

\begin{tabular}{c|c|c|c}
\hline $\begin{array}{c}\text { ROM at 6 weeks } \\
\text { (Hip \& knee) }\end{array}$ & $\begin{array}{c}\text { Group A (n= 32) } \\
\text { Hip spica cast }\end{array}$ & $\begin{array}{c}\text { Group B (n= 32) } \\
\text { Initial traction } \\
\text { followed by hip } \\
\text { spica cast }\end{array}$ & P value \\
\hline Free & $4(12.5 \%)$ & $6(18.75 \%)$ & \\
Decreased by $20^{\circ}$ & $26(81.25 \%)$ & $24(75 \%)$ & 0.592 \\
Decreased by $>20^{\circ}$ & $2(6.25 \%)$ & $2(6.25 \%)$ & \\
\hline
\end{tabular}

Quadriceps wasting at 6 weeks: Among children in group A $4(12.5 \%)$ children had no wasting whereas $26(81 \%)$ and $2(6.25 \%)$ had mild to moderate and severe wasting respectively. Among children in group B no wasting was seen in $6(18.75 \%)$ cases, $24(75 \%)$ had mild to moderate wasting and $2(6.25 \%)$ had severe wasting.

Table 5: Quadriceps wasting at 6 weeks

\begin{tabular}{c|c|c|c}
\hline $\begin{array}{c}\text { Quadriceps } \\
\text { wasting at 6 } \\
\text { weeks }\end{array}$ & $\begin{array}{c}\text { Group A }(\mathbf{n}= \\
\text { 32) Hip spica } \\
\text { cast }\end{array}$ & $\begin{array}{c}\text { Group B (n= 32) } \\
\text { Initial traction } \\
\text { followed by hip } \\
\text { spica cast }\end{array}$ & P value \\
\hline No wasting & $4(12.52 \%)$ & $6(18.75 \%)$ & \\
Mild to moderate & $26(81.25 \%)$ & $24(75 \%)$ & 0.529 \\
Severe & $2(6.25 \%)$ & $2(6.25 \%)$ & \\
\hline
\end{tabular}

Average duration of hospital stay was 1.65 days and 11.65 days in group A and Group B respectively. Average total time of spica cast application was 45.13 days and 49.41 days in group A and group B patients respectively.

Table 6: Average hospital stay and Total time of Hip Spica Cast

\begin{tabular}{c|c|c}
\hline Group & Hospital stay (Days) & P value \\
\hline $\mathrm{A}(\mathrm{n}=32)$ & 1.65 & 0.01 \\
$\mathrm{~B}(\mathrm{n}=32)$ & 11.67 & \\
\hline
\end{tabular}

Table 7: Total time of Hip Spica Cast

\begin{tabular}{c|c|c}
\hline Group & Total time of Hip Spica Cast & P value \\
\hline $\mathrm{A}(\mathrm{n}=32)$ & 45.13 & 0.01 \\
$\mathrm{~B}(\mathrm{n}=32)$ & 49.41 & \\
\hline
\end{tabular}

\section{Discussion :}

Femoral shaft fractures can occur in children of all ages. They account for $1.6 \%$ of all childhood fractures, and they lead to significant impact on the child and family ${ }^{1}$. Various method for treating femur shaft fractures in children are Pelvic harness, padding, hip spica cast, skin traction (can be followed by hip cast), skeletal traction, elastic intramedullary nails, semi-rigid pediatric locking nail, submuscular ${ }^{11,12}$. This study analyses the results of two different non-operative treatment of femoral shaft fracture in children 6 months to 10 years. The first one, consisting of immediate reduction and early hip spica casting and the second corresponds to Initial traction followed by hip spica cast. Closed diaphyseal fractures of femur in children are usually treated by initial traction by 7-21 days followed by an additional period of immobilization in hip spica till the union occurs.However treatment like this would lead to prolonged hospital stay resulting in increasing cost and occupancy of hospital beds. In addition, such treatment would also lead to an extended period of patient's separation from their families. Immediate and early closed reduction and hip spica casting is an acceptable nonsurgical treatment for childrenwith isolated femoral shaft fractures, especially those younger than 10 years of age ${ }^{14,15}$. In our study no significant difference in limb length discrepancy, angulation, range of movements and Quadricep wasting at 6 weeks was seen among two groups, however a significant difference in hospital stay duration ( $p$ value 0.01 ) and total time of spica cast application ( $p$ value 0.01 ) was seen among two groups. Hip spica cast is simple, safe, effective, cheap and definitive method of treatment and does not need prolonged hospital stay. Results of our study are comparable with other studies. Studies by Faheem et al ${ }^{16}$, Allen et al. ${ }^{17}$, Staheli and Sheridan ${ }^{18}$, Splain and Denno $^{19}$, Sugi and Cole ${ }^{20}$, Henderson et $\mathrm{al}^{21}$ did not find much difference in outcome between early spica cast and skin traction followed by spica cast. With increasing number of patients, the availability of beds is a problem in our setup. There are encouraging results with spica cast from many 
Volume 2, Number 1, January 2020

years. Hip spica cast avoids prolonged hospitalization thus reducing cost of treatment and allows rapid return of a child to family environment

\section{Conclusion:}

Hip spica cast is simple and effective method of treatment. A satisfactory outcome can be achieved by any of the two methods. Hip spica cast avoids prolonged hospitalization thus reducing cost of treatment and reduces occupancy of hospital beds. Hip spica cast also avoids complications related to traction and operative treatment methods. The results achieved with both the non operative methods of treating the closed diaphyseal fractures of femur in children are nearly same, that is insignificant. So we feel that in our setup, hip spica cast is the best method for treating the closed diaphyseal fractures of femur in children.

\section{References:}

1. Beaty JH, Kasser JR (Eds): Rockwood and Wilkins' Fractures in Children (6th Edition). Lippincott Williams \& Wilkins, PA, USA (2006).

2. Cusick L, Thompson NW, Taylor TC, Cowie GH. Paediatric femoral fracturesthe Royal Belfast Hospital for Sick Children experience. Ulster Med J 2005; 74: 98-104.

3. Davis TJ, Topping RE, Blanco JS (1995) External fixation of pediatric femoral fractures. Clin Orthop Relat Res: 191-198.

4. Hedlund $R$, Lindgren $U$. The incidence of femoral shaft fractures in children and adolescents. J Pediatr Orthop 1986; 6(1): 47-50

5. Daly KE, Calvert PT. Accidental femoral fracture in infants. Injury 1991; 22(4): 337-8.

6. McGraw-Hill. Fracture of the femoral shaft. In: Simon R, Koenigsknecht SJ (eds.) Emergency Orthopedics the extremities (5th edn) 2007: 391.

7. Kasser J. Femoral shaft fractures. In: Rockwood CA Jr, Wilkins KE, Beaty JH (eds.) Fractures in children (4th edn) USA: Lippincott-Raven 1996: 1195-1201.

8. Skinner HB, Edward D, Gosselin R, Lowenberg DW. Musculoskeletal Trauma Surgery. In: Skinner HB (ed) Current diagnosis and treatment in orthopedics (2nd edn) USA: McGraw-Hill 2000: 114

9. Worth TD. Fractures and dislocations. In: James Kyle (edt) Pye's Surgical Handicrafts. UK: John Wright \& Sons Ltd 1984: 243.

10. Heyworth BE, Suppan CA, Kramer DE, Yen YM. Management of pediatric diaphyseal femur fractures. Curr Rev Musculoskelet Med. 2012(5):120-5.

11. Kanlic E, Cruz M. Current concepts in pediatric femur fracture treatment. Orthopedics. 2007; 30 (12): 1015-9.

12. John MF. Current treatment options for pediatric femur fractures. U.P Orthopdic Journal 1998; 11: 12.

13. Kocher MS, Sink EL, Blasier RD, et al. American Academy of Orthopaedic Surgeons clinical practice guideline on treatment of pediatric diaphyseal femur fracture. J Bone Joint Surg Am 2010; 92(8): 1790-2.

14. Buckley SL. Current trends in the treatment of femoral shaft fractures in children and adolescents. Clin Orthop 1997; 338: $60-73$.

15. Infante AF Jr, Albert MC, Jennings WB, Lehner JT. Immediate hip spica casting for femur fractures in pediatric patients: a review of 175 patients. Clin Orthop 2000; 376:106-12.

16. Faheem Ahmed Memon ,Hamadullah Soomro, Saira Baloch and Bikha Ram Devrajani. Treatment of Closed Diaphyseal Fractures of Femur in Children Comparative Study between Hip Spica \& Initial Traction Followed By Hip Spica Cast. Orthop Muscular Syst 2016; 5:2

17. Allen BL Jr, Kant AP, Emery FE. Displaced fractures of the femoral diaphysis in children. Definitive treatment in a double spica cast. J Trauma 1977; 1: 8-19.

18. Staheli LT, Sheridan GW. Early spica cast management of femoral shaft fractures in young children. A technique utilizing bilateral fixed skin traction. Clin Orthop Relat Res 1977; 162166.

19. Splain SH, Denno JJ. Immediate double hip spica immobilization as the treatment for femoral shaft fractures in children. J Trauma 1958; 25: 994-996.

20. Sugi M, Cole WG. Early plaster treatment for fractures of the femoral shaft in childhood. J Bone Joint Surg Br 1987; 69: 743-745.

21. Henderson OL, Morrissy RT, Gerdes MH, McCarthy RE. Early casting of femoral shaft fractures in children. J Pediatr Orthop 1984; 4: 16-21 